\title{
Sustainability through digitalization: European strategy
}

\author{
Sergey Kamolov ${ }^{1, *}$, and Igor Stepnov ${ }^{1,2}$ \\ ${ }^{1}$ Moscow State Institute of International Relations (MGIMO University), Prospect Vernadskogo, 76, \\ 119454 Moscow, Russia \\ ${ }^{2}$ Financial University under the Government of the Russian Federation, Leningradsky Prospekt, 49, \\ 125993 Moscow, Russia
}

\begin{abstract}
The process of digitalization is quick, unstoppable and it is moving in unpredictable directions. Hence, governments and policymakers should shape a digital future that makes the most of the great opportunities that digital transformation offers, in order to improve people's lives and boost economic growth for countries, while ensuring that nobody is left behind, i.e. secure sustainable development. The "Digital Agenda for Europe", which was developed after the 2008-2009 economic crisis, served as a framework for ICT and digitalization to boost European economy and sustainable growth. We present the research how the European Digital Agenda is integrated with sustainable goals of "Europe 2020".
\end{abstract}

\section{Introduction}

Information and Communication Technologies drive most of social and economic activities in a "digital" way. Social networks allow us to be constantly online and able to communicate with people in every corner of the world. In 2018, Facebook had 2.2 billion users. Physical devices connect and exchange data - the concept of "Internet of Things [1]" - and we are rapidly evolving into the "Internet of Everything", a more complex system that will bring together people, processes and data. Ericcson is forecasting the number of cellular IoT connections is expected to reach 3.5 billion in 2023. E-government solutions allow citizens to have a closer relation with Public Administration Systems [2].

However, such benefits also come with new challenges, since the digital transformation is changing the basic structure of governments, economies and societies, and therefore raises doubts and concerns about jobs and skills, privacy, security [3] and social inclusion. From an institutional point of view, some countries have already adjusted the governmental structures to focus on digitalization, such as the "Ministry of Digital Affairs" of Poland, the "Federal Ministry of Transport and Digital Infrastructure" of Germany and the "Ministry of Digital Development, Communications and Mass Media" of the Russian Federation.

Realising the opportunities and addressing the challenges of the digital transformation is not an automatic process, but requires policy action to make it work for the growth and well-being. This is the reason why in the latest years digital strategies have been developed

\footnotetext{
* Corresponding author: s.kamolov@inno.mgimo.ru
} 
at different levels of governance. The European Union provides a vivid example of this. In order to relaunch the European economy after the devastating financial crisis of 2008-2009, in 2010 EU institutions issued a strategic document - the Digital Agenda for Europe which describes the path to be followed in order to spread the benefits of the digital era to the whole society within 2020. This document defines the main areas in which it is most necessary to take action, provides some definite objectives and proposes some concrete policy initiatives.

27 Member States of the EU show differences in terms of economic and technological development. Despite following the path laid out by European Union institutions, each Member State needs to focus on the peculiarities that characterize it. The Digital Agenda for Europe will be analysed, in the light of the initiatives set out and the progress made in the latest years, in order to evaluate achievements, shortcomings and aspects that may be improved. Practical value of the study consists in the detailed research that has been carried out throughout numerous policy documents, in order to understand and evaluate how the complex Digital Agenda for Europe is being implemented in concrete terms. However, the risk is that of using a too wide approach, which does not take into consideration the specificities of each Member State, and of regional areas as a consequence. The subject of the research was elaborated by Ripalvella M. (2016) [4], Matteucci N. (2016) et al. [5] who studied interconnections between EU and national digital strategies.

The goal of the present study is to evaluate at what level of governance digital policies are better developed and implemented, through the assessment of results scored by the EU. We analyse the key action areas of the Digital Agenda for Europe, through the study of the most recent initiatives put in place and assess the Digital Agenda for Europe, considering its focus on citizens and sustainability.

\section{Materials and Methods}

In the empirical part, methods of observation and measurement were used. In the theoretical part of the study and discussion, methods of analysis and synthesis of information, comparison and generalization are used.

We introduce a hypothesis that after 2008-2009 global financial crisis, in order to achieve the goals of the "Europe 2020" Strategy the EU put the emphasis on Digital Agenda reaching "Smart", "Sustainable [6]" and "Inclusive" growth. "A digital agenda for Europe" is a cutting-through idea for other six flagship European initiatives: "Innovation Union", "Youth on the move", , "Resource efficient Europe", "An industrial policy for the globalisation era", "An agenda for new skills and jobs", "European platform against poverty".

We decompose the EU targets to see sustainability drivers in Digital Agenda, as the European Commission avoided the adoption of a "one size fits all" approach and each Member State had the opportunity to adapt EU goals and transform them in national targets, policies and activities. We studied the matter in the context of eight targets that describe how the European Union should look like, according to the indicators taken into consideration, by the year 2020 :

- Increase of the employment rate of the population aged 20-64 to at least $75 \%$;

- Invest 3\% of GDP in R\&D;

- Reduce of greenhouse gas emissions to at least 20\% compared to 1990 levels; increase the share of renewable energy use to $20 \%$; increase energy efficiency to $20 \%$;

- Reduce of the dropout rate to $10 \%$ and increase the rate of the population aged 30-34 having completed tertiary education to $40 \%$;

- Reduce of the number of people living below national poverty lines to $25 \%$. 


\section{Results and Discussion}

The main document which puts in place the project of a European Digital Agenda is the "Communication from the Commission to the European Parliament, the Council, the European Economic and Social Committee and the Committee of the regions: A digital agenda for Europe", officially registered as $\operatorname{COM}(2010) 245$ final/2, published in Brussels on $26^{\text {th }}$ August 2018. The objective of this Agenda is to "chart a course to maximise the social and economic potential of ICT, most notably the Internet, a vital medium of economic and societal activity [7]". The European Commission identified seven obstacles that are jeopardizing the objective of creating a "Digital Europe" which are:

- Fragmented digital markets: despite all achievements of the digital economy, to this day in the European Union there is not a digital single market.

- Lack of interoperability: where "interoperability" can be defined as the ability of systems, networks, applications or components, to exchange and to make use of data. ICT play an essential role in the establishment of a system of "pan-European" governance - a network of local and national administrations across the EU, abled to share information and services [8]. However, Europe is still weak in setting standards for digital public administration.

- Rising cybercrime[9] and risk of low trust in networks [10]: European citizens are exposed to new threats and they will not engage in online activities unless they feel safe.

- Lack of investment in networks: especially in the broadband network infrastructure.

- Insufficient research and innovation efforts: the lack of investments in this field, together with failure in exploiting the creativity of its SME and in converting ideas into innovations.

- Lack of digital literacy[11] and skills: citizens of the different Member States of the European Union lack, to varying degrees, digital knowledge and competences.

- Missed opportunities in addressing global challenges: climate change, ageing population.

The seven challenges have been of essential importance to the European Union and were reflected in respective key actions.

Action area 1: A vibrant digital single market. "The Internet is borderless, but online market, both globally and in the EU, are still separated by multiple barriers affecting not only access to pan-European telecom services but also to what should be global internet services and content [7]".

Open access to content is the core of the EU online markets which still suffer from multiple barriers, preventing free circulation of content and services across. Facilitation of cross-border licensing and creation of a pan-European licensing system in the audiovisual sector, which protects the freedom of right-holders are the instruments of creation, production and distribution of digital content. Therefore on $6^{\text {th }}$ May 2015 a Communication of the European Commission addressing the need to develop "A digital single market strategy for Europe" was issued [12] followed two years later, on $10^{\text {th }}$ May 2017, by the "Mid-term review on the implementation of the Digital Single Market Strategy". The progress was identified in the following spheres:

- In 2017 the EU ended roaming surcharges for all citizens who travel periodically within the EU, following the Commission Implementing Regulation n. 2016/2886 of 15 December 2016 "laying down detailed rules on the application of fair use policy and on the methodology for assessing the sustainability of the abolition of retail roaming surcharges and on the application to be submitted by a roaming provider for the purposes of that assessment [13]", commonly named "Roam like at home".

- To address the problem of geo-blocking (the practice of restricting access to internet content based upon the user's geographical location) the European Union introduced the 
Regulation (EU) n. 2018/302 [14] which allowed customers who were not able to purchase goods and services from e-stores located in a different Member State than the e-applications country of origins ("unjustified geoblocking").

- On 25 May 2018 the "General Data Protection Regulation [15]" entered into force and introduced new rules to protect the data of European citizens online while reducing burdens for companies and public entities. The main aim of this regulation is to strengthen European citizens' fundamental rights of protection of their personal data, as stated by Article 8(1) of the Charter of Fundamental Rights of the European Union and Article 16(1) of the Treaty on the Functioning of the European Union. The main novelties set forth by the GDPR include the "right to be forgotten", which allows any individual to have their data deleted when he does not wish them to be processed anymore. A specific protection has been established for children, since they are considered to be less aware of risks and consequences related to the use of their personal data. For what concerns business, the regulation provides clarity of the rules to be applied and it supports the development of the Digital Single market, since companies have now to respect just one law for data protection, which also applies to companies established outside the EU but doing business in the European Single Market. However, the results achieved so far and the proposals which need to be approved in the next future do not go far enough in promoting regulatory homogeneity and will not allow EU member states to exploit all the advantages of digitization any time soon. European digital markets remain often segmented along national lines and also new regulation under the DSM umbrella tend to conform to the political desires of many who would like to slow new digital market competition down.

Erixon and Lamprecht [16] individuate some conceptual problems that have hampered the realization of the Digital Single Market. They propose to include in the Digital Single Market Agenda more non-digital market reforms. Instead of "prescriptive" regulations ("what one should do"), the EU can set more "proscriptive" regulations ("what actors cannot do") providing for a lower degree of regulatory complexity. The regulatory focus should be targeted on prevention of fragmentation of the Digital Single Market and better coordination of various data-regulations.

Action area 2: Interoperability and standards. Standards are vital for interoperability. There is the risk that the EU countries may create isolated digital environments and electronic barriers that could prevent public administrations from connecting with each other. Interoperability should be enhanced through coordination at European and national level. Public administrations eager to collaborate with each other and with businesses and citizens, and to see information flows seamlessly across borders to support a digital single market in Europe. In 2010 the first version of the "European Interoperability Framework for European public services [17]" was adopted. It is an agreed approach to interoperability for organisations that wish to work together towards the joint delivery of public services and contains guidance and recommendations that Member States, which wish to operate at a Pan-European level, should follow, for the ultimate benefit of citizens and businesses.

Further on the specific recommendations on interoperability principles and models were delivered in 2017 in so-called "ISA" ${ }^{2}$ " programme [18]. Misuraca et al. [5] highlight the importance of the local dimension, with its distinctive characteristics as a layer of government. In Europe most public services are provided at city or regional level by municipalities or regional institutions, where we see structural and cultural diversity. The design of an interoperability framework must deal with technical, organizational, institutional and socio-economic issues.

Action area 3: Trust and security. The European Union believes that it's a shared responsibility to make the digital society more safe. Among the key actions advanced back in 2010 there was the development of Network and Information Security Policy (NIS Directive was issued on 6 July 2016 [19]), which comprised: 
- Obligations for Member States for the adoption of a national strategy on security of NIS;

- Creation of a Cooperation Group, with the task of supporting and facilitating cooperation through information exchange;

- Creation of a "Computer security incident response teams" network, to enhance trust and confidence between Member States;

- Establishment of security and notification requirements for digital service operators and providers;

- Obligations for Member States to designate national competent authorities that will deal with security of network and IT systems.

Important step forward was the agreement reached on 10 December 2018 by the European Parliament, the Council and the Commission on the text of the "Cybersecurity Act [20]", setting of the new EU strategy for cybersecurity and strengthening EU resilience against attacks, of creating a digital market for cybersecurity and of increasing trust of consumers in digital technologies.

Action area 4: Fast and ultra-fast Internet access. To guarantee universal broadband coverage with increasing speeds, deployment of Next Generation Access networks and open and neutral character of the Internet, there were core initiatives put in place:

- "Connectivity for a Competitive Digital Single Market - Towards a European Gigabit Society [21]". Strategy, underlining important role of private investment in networks to reach digital progress, setting up goals for 2025 when all schools, transport hubs and providers of public services should have access to ultrafast internet connections (1 Gigabit of data per second). All European households, both rural and urban, ought to have access to networks with a speed of at least $100 \mathrm{Mbps}$. Finally, all major roads and railways should have $5 \mathrm{G}$ wireless coverage.

- Establishment of the European Electronic Communications Code [22], which sets forth common rules and objectives on the regulation of the telecom industry. The Code has to be transposed into national legislation within December 2020.

- "5G for Europe Action Plan [23]" in 2016. Support the deployment of 5G through implementation of radio spectrum assignment policies and investment incentives.

Action area 5: Research and innovation. "Innovation Union" was a flagship initiative of EU Strategy Europe 2020. The financial means to implement it was a "Horizon 2020" - the widest EU Research and Innovation programme, with $€ 80$ billion funds available from 2014 to 2020.

Action area 6: Enhancing digital literacy, skills and inclusion. The share of households in the EU-28 having Internet access was just $55 \%$ in 2007 , but reached $87 \%$ by 2017 , however with relevant differences among Member States. The percentage of people that had never used the Internet in 2017 was $13 \%$, while ten years before it reached $37 \%$ of EU population. The evolution of the digital society carries the risk that instead of reducing, the already existing "digital divide", both at EU and national level, will increase. This issue is addressed through two major initiatives adopted in 2016: "A new skills agenda for Europe [24]" and "Digital Skills and Jobs Coalition", aiming at trainings, job placements and internships in the digital sphere. The final objective is to reduce the digital skills gap in Europe.

Action area 7: ICT-enabled benefits for EU society. Powerfulness of ICT allows the EU use its potential to address global challenges:

- Climate change: the ICT sector plays a leading role in the achievement of a more energy-efficient and sustainable economy. The ICT sector accounts for $8-10 \%$ of the European electricity consumption and up to $4 \%$ of its carbon emissions, but on the other hand ICT offer potential for a structural shift to less resource-intensive products and 
services, for energy saving in buildings and electricity networks, as well as for more efficient and less energy consuming intelligent transport systems [25].

- Ageing population: digital technology can support people who are ageing in many different ways. It is foreseen that by 2060 the European economy will turn into a "Silver economy" - one in three Europeans will be over 65. It is clear that the European Union should adequately prepare to this future scenario through the numerous opportunities offered by digital technologies, to turn it into a "Smart Silver Economy".

- Digital cultural heritage: "Europeana" is the European Commission platform for cultural heritage which contains a digital library, archive and museum. It provides access to 53 million items (image, text, sound, video, etc.) coming from over 3700 libraries, archives, museums. However, besides making cultural heritage widely available, the digital technology can also revolutionise cultural tourism [26], through specific applications that provide to users useful information about heritage sites.

\section{Conclusions}

The Digital Agenda for Europe is very ambitious and complex, since it encompasses numerous policy sectors and plays important role in sustainable development of the European Economic Zone. However, Goodwin \& Spittle, while examining the critical studies of language and information policy, found out that one common aspect which emerged is "that there is a demonstrable gap between the way in which political actors describe technological, social and cultural change [...] and the reality of the situation [27]". According to Mansell [28], the Digital Agenda has failed to meet the demands of the various stakeholders, without making an effort to take into consideration citizens' interests alongside those of market players. Verdegem [29] also argues that traditional digital policies - among which we can include the Digital Agenda - suffer from technological determinism, which is a vision of ICT as the most important driver of the increase in societal prosperity, enabling the global use of new communication technologies that will eventually lead to a massive social and economic transformation.

Another aspect that was highlighted in the debate concerning digital policies is that the impact of the digital revolution on labour markets and workers' rights and interests is hardly touched upon in the related policy documents [30][31]. The main concern of the European Services Workers Union is about the social shortcomings that affect the Commission's digital agenda, which is viewed as too narrow in its focus and lacking a social dimension based on the principles of empowerment, inclusion and cohesion. "Empowerment" means that all Europeans should have the right to shape the digital revolution according to their needs and ambitions and that the process of digitalization should not result in an un-inclusive project. Furthermore, the process of digitalisation should lead to "cohesion [32]" and contribute to solidarity throughout Europe, while it risks becoming another source of social inequality and political and economic imbalances in Europe. Indeed important differences still exist among and within Member States in the implementation of the general guidelines to digitalization provided at EU level. "Inclusiveness" refers to making the digital world accessible to everybody. Another important aspect highlighted in the assessment is that citizens should not be forced to accept all forms of digital change. It is an important element of socially balanced digital policy. However, this idea is not reflected in some of the principles promoted in digitalization strategies, for example the principle of "switch-off" - which refers to the phenomenon that takes place when a Public Administration stops to deliver a service through traditional channels, in favour of an exclusive digital management, is being implemented in the Italian Digital Agenda [33]. 
Finally, e-government is undoubtedly future-driven example of how ICT can improve the relationship between businesses, citizens and the government for sustainability. On April 2016 the European Commission launched the "EU eGovernment Action Plan 20162020", as an effective instrument to prevent further fragmentation of the Digital Single Market that could arise from the process of modernisation of PA and to tackle the challenges that hamper the full effectiveness of eGovernment solutions. In the new Action Plan the policy priorities focus on the cross-border interoperability of online services and on the facilitation of digital interaction between administrations, citizens and businesses [34].

\section{References}

1. I. Woungamg, S. K. Dhurandher, A. Visconti, Internet of Things: design, architectures and protocols (2019)

2. J. D. Twizeyimana, A. Andersson, Government Information Quarterly, 36, 167 (2019)

3. B. Akhgar, H. Arabnia, Emerging Trends in ICT Security (2013)

4. M. Ripalvella, Rapporto Economico e Sociale (2016)

5. N. Matteucci, The infrastructure digital divide of Marche Region (2015)

6. A. Balisacan, U. Chakravorty, M. Ravago, Sustainable Economic Development (2014)

7. European Commission, Communication from the Commission to the European Parliament, the Council, the European Economic and Social Committee and the Committee of the Regions, A Digital Agenda for Europe, COM(2010) 245 final/2, Brussels (2010)

8. G. Misuraca, G. Alfano, G. Viscusi, Journal of theoretical and applied electronic commerce research, 6(1), 96 (2011)

9. S. Moskowitz, Cybercrime and Business (2017)

10. A. Davoudi, M. Chatterjee, Online Social Networks and Media, 7, 1 (2018)

11. T. Welsh, M. Wright, Information Literacy in the Digital Age (2010)

12. European Commission, Communication from the Commission to the European Parliament, the Council, the European Economic and Social Committee and the Committee of the Regions, A Digital Single Market Strategy for Europe, COM(2015) 192 final, Brussels (2015)

13. Official Journal of the European Union, 2016/2286 (2016)

14. Official Journal of the European Union, Regulation, 2018/302 (2018)

15. Official Journal of the European Union, 2016/1148 (2016)

16. Official Journal of the European Union, 2016/679 (2016)

17. European Commission, Communication from the Commission to the European Parliament, the Council, the European Economic and Social Committee and the Committee of the Regions, "Towards interoperability for European public services", $\operatorname{COM}(2010) 744$ final, Brussels (2010)

18. Official Journal of the European Union, 2015/2240 (2015)

19. Official Journal of the European Union, 2016/1148 (2016)

20. European Commission, Joint Communication to the European Parliament and the Council, "Resilience, Deterrence and Defence: Building strong cybersecurity for the EU”, JOIN(201) 450 final, Brussels (2017) 
21. Communication from the Commission to the European Parliament, the Council, the European Economic and Social Committee and the Committee of the Regions, Connectivity for a Competitive Digital Single Market - Towards a European Gigabit Society", COM(2016) 587 final, Brussels (2016)

22. Official Journal of the European Union, 2018/1972 (2018)

23. Communication from the Commission to the European Parliament, the Council, the European Economic and Social Committee and the Committee of the Regions, "5G for Europe: An Action Plan", COM(2016) 588 final, Brussels (2016)

24. European Commission, Communication from the Commission to the European Parliament, the Council, the European Economic and Social Committee and the Committee of the Regions, "A new skills agenda for Europe. Working together to strengthen human capital, employability and competitiveness", $\operatorname{COM}(2016) 381$ final, Brussels (2016)

25. Z. Karami, R. Kashef, Transportation Engineering, 2 (2020)

26. M. Sigala, Tourism Management Perspectives, 25, 151 (2018)

27. I. Goodwin, S. Spittle, New Media \& Society, 228 (2002)

28. R. Mansell, The European digital agenda: for whom? (2013)

29. P. Verdegem, TripleC, Information Society Policies 2.0. A critical analysis of the potential and pitfalls of social computing \& informatics in the light of e-inclusion, 139 (2010)

30. S. Clauwaert, S. De Spiegelaere, A. Hoffmann, R. Jagodzinski, A social Europe needs workers' participation, 60 (2016)

31. S.Austriaco, Digitalisation and its economic and social potentials, 2 (2015)

32. S.Alexiadis, Habitat International, 68, 75 (2017)

33. M. Benedetti, Lo switch off digitale nella PA: tra casi di eccellenza e forti difficoltà (2019)

34. Communication from the Commission to the European Parliament, the Council, the European Economic and Social Committee and the Committee of the Regions, "EU eGovernment Action Plan 2016-2020. Accelerating the digital transformation of government", COM(2016) 179 final, Brussels, p. 9. (2016) 